\title{
Photosynthetic characteristics and growth performance of lettuce (Lactuca sativa L.) under different light/dark cycles in mini plant factories
}

\author{
J. ZHOU*, J.Z. WANG*, T. HANG*, and P.P. LI",+ \\ Key Laboratory of Modern Agricultural Equipment and Technology, Ministry of Education \& Jiangsu Province, \\ Jiangsu University, 212013 Zhenjiang, China* \\ Nanjing Forestry University, 210037 Nanjing, China**
}

\begin{abstract}
We investigated the photosynthesis and growth of lettuce (Lactuca sativa L.) grown under three light/dark cycles in a mini plant factory with artificial illumination. A relative longer light cycle [12/12 h (light/dark)] increased not only lightresponse curve parameters, such as light-saturated net photosynthetic rate, light-saturation point, light-compensation point, dark respiration rate, but also upregulated $\mathrm{CO}_{2}$-response curves parameters, such as $\mathrm{CO}_{2}$-saturated net photosynthetic rate, initial carboxylation efficiency, and photorespiration rate, compared to those of the shorter light cycles $[6 / 6 \mathrm{~h}$ and $3 / 3 \mathrm{~h}$ (light/dark)]. A longer light cycle enhanced electron transfer potential, increased the chlorophyll amount, leaf area, and biomass and reduced the root/shoot ratio and the specific leaf area. Our results imply that the prolonged light cycle led to the increase in photosynthetic capacity and significantly enhanced the growth rate of lettuce.
\end{abstract}

Additional key words: biomass accumulation; chlorophyll fluorescence; leaf gas exchange; morphogenesis; photoperiod.

\section{Introduction}

As one of the most important environmental factors for plant production, light provides the energy to induce various physiological responses of plants (Abidi et al. 2012). Lettuce (Lactuca sativa L.) is often used as a model crop in studying plant responses to the light environment due to its rapid growth, short growth cycle, low energy demands, high nutritional value, and stable yields (Křístková et al. 2008, Li and Kubota 2009, Lin et al. 2013). The light/dark period is one important component of light conditions. The light/dark cycle refers to the alternation of light and dark periods within a circadian cycle. Many studies have shown that light/dark periods play an important role in regulating lettuce photosynthetic characteristics and growth performance (Koontz and Prince 1986, Gaudreau et al. 1994, Kitaya et al. 1998, Park et al. 2012, Zhang et al. 2018, Yan et al. 2019). Contents of some secondary metabolites also appear to be influenced by the light/dark periods. A previous study showed that the leaves of vegetable plants contained the highest content of betacyanin, chlorophyll ( $\mathrm{Chl}$ ), total polyphenol, and antioxidant activity under a $12 / 12-\mathrm{h}$ photoperiod compared to $6 / 18,8 / 16$, and $24 / 0 \mathrm{~h}$ (Ali et al. 2009).

A plant factory with artificial light (PFAL) is regarded as the best model of modern protected horticulture because of its precise management of most environmental factors (i.e., temperature, humidity, light intensity and quality, and duration of photoperiod) (Miyagi et al. 2017). A mini plant factory with artificial illumination (mini-PFAL) is a household PFAL system, which further concentrates the plant factory technology into a closed-loop refrigeratorsized environment (Takagaki et al. 2016). A PFAL for plant production has several potential benefits, such as higher quality pesticide-free plants, a shorter production period, and higher light energy-use efficiency compared to traditional greenhouse and field cultivation (Kozai 2013a,b). The light/dark period in the PFAL is not limited by the traditional concept of a circadian cycle and can be segmented into several short light/dark cycles based on a certain ratio. These short light/dark cycles consume the same amount of electricity per day as a light/dark period.

\footnotetext{
Received 8 October 2019, accepted 4 February 2020.

${ }^{+}$Corresponding author; e-mail: lipingping@ujs.edu.cn

Abbreviations: $A_{\mathrm{Nmax}}-\mathrm{CO}_{2}$-saturated net photosynthetic rate; $\mathrm{AQY}$ - apparent quantum efficiency; $\mathrm{CE}$ - initial carboxylation efficiency; $C_{\mathrm{i}}$ - intercellular $\mathrm{CO}_{2}$ concentration; $C_{\text {isat }}-\mathrm{CO}_{2}$-saturation point; $\mathrm{DM}$ - dry mass; $\mathrm{F}_{0}$ - minimal fluorescence yield of the dark-adapted state; $F_{m}$ - maximal fluorescence yield of the dark-adapted state; $F M-$ fresh mass; $F_{v}-$ variable fluorescence; $F_{v} / F_{m}-$ maximal quantum yield of PSII photochemistry; LA - leaf area; LCP - light-compensation point; LED - light-emitting diode; LSD - least significant difference; LSP - light-saturation point; PFAL - plant factory with artificial light; $P_{\mathrm{N}}-$ net photosynthetic rate; $P_{\mathrm{Nmax}}-$ light-saturated net photosynthetic rate; $R^{2}$ - coefficient of determination; $R_{\mathrm{D}}$ - dark respiration rate; $R_{\mathrm{P}}$ - photorespiration rate; SLA - specific leaf area; $\mathrm{SPAD}$ - unitless value obtained with the SPAD-502 chlorophyll meter; $\Gamma^{*}-\mathrm{CO}_{2}$-compensation point.

Acknowledgements: The research was supported by the Natural Science Foundation of Jiangsu Provincial Department of Education (17KJA416002), China Postdoctoral Science Foundation (2015M580400), Jiangsu Province Postdoctoral Science Foundation (1501112B) and Jiangsu Province Graduate Research Innovation Program of Universities (KYLX15_1084). It is funded by the Priority Academic Program Development of Jiangsu Higher Education Institutions.
} 
In areas where electricity costs vary widely at different times of the day, the irradiance mode of short light/dark cycles can be used to provide light to plants when the price of electricity is low (Hang et al. 2019).

However, a short light/dark cycle breaks the traditional day-night pattern and is inevitably different from a light/dark period in its effects on the physiological and growth characteristics of plants. Different studies have described the growth of lettuce under varying light/dark cycle conditions. Ishii et al. (1995) reported the growth characteristics and nutrient uptake of lettuce plants grown under three light/dark cycles for $2.67 / 5.33 \mathrm{~h}, 4 / 8 \mathrm{~h}$, and $8 / 16 \mathrm{~h}$ (light/dark). Their results demonstrated that lettuce plants grown under $2.67 / 5.33 \mathrm{~h}$ and $4 / 8 \mathrm{~h}$ had fewer leaves, lower fresh and dry masses, smaller leaf area (LA), and lower water and mineral uptakes compared to plants grown under 8/16 h. Hang et al. (2019) reported the dynamic changes in lettuce LA under three light/dark cycles of $3 / 3 \mathrm{~h}, 6 / 6 \mathrm{~h}$, and $12 / 12 \mathrm{~h}$ (light/dark). Their results showed that under a light/dark period of 12/12 h, lettuce leaves were more slender and the leaf angle was steeper compared to plants grown under $6 / 6 \mathrm{~h}$ and $3 / 3 \mathrm{~h}$. In addition, a relatively longer light cycle of $6 / 6 \mathrm{~h}$ increased leaf stomatal conductance $\left(g_{\mathrm{s}}\right)$, net photosynthetic rate $\left(P_{\mathrm{N}}\right)$, and biomass compared to plants grown under a shorter light cycle of $3 / 3 \mathrm{~h}$.

These studies indicate that short light/dark cycles alter the morphogenesis, nutrient uptake, and biomass accumulation of lettuce compared to a light/dark period. However, relevant research on the parameterization of the response of gas exchange to different light/dark cycles has not been conducted. This lack of data has limited the development and application of predictive models of lettuce productivity in PFAL production systems. The light- and $\mathrm{CO}_{2}$-response curves describe the relationship between $P_{\mathrm{N}}$ and PPFD; $P_{\mathrm{N}}$ and $\mathrm{CO}_{2}$ as analytical tools widely used for the ecophysiological characterization of gas exchange at the leaf level may represent useful criteria for controlling the environment and are required tools for simulation models designed to predict potential plant behavior in response to environmental conditions (Noda et al. 2004, Wang et al. 2006, Avola et al. 2008, Xu et al. 2013). Chl fluorescence continues to be a primary means for studying photosynthetic regulation and plantenvironment responses due to its sensitivity, convenience, and nondestructive properties (Rascher et al. 2000, Dai et al. 2009). Hence, the objectives of this research were to calculate and compare the coefficients of the light- and $\mathrm{CO}_{2}$-response curves and $\mathrm{Chl}$ fluorescence parameters under different light/dark cycles and to identify the optimal light/dark cycle for growth to achieve the biomass accumulation and distribution required for selected lettuce plants. Two hypotheses were tested: (1) Based on the fact that photosynthesis is hampered under short light cycle conditions, light-saturated net photosynthetic rate $\left(P_{\text {Nmax }}\right)$ and $\mathrm{CO}_{2}$-saturated net photosynthetic rate $\left(A_{\mathrm{Nmax}}\right)$ would decrease as the light cycle duration decreases. (2) Lettuce plants under different light/dark cycles would exhibit different above- and belowground biomass accumulations.

\section{Materials and methods}

Plant materials and growth conditions: All the experiments were conducted at Jiangsu University, Zhenjiang, China. Romaine lettuce (Lactuca sativa L.) was selected as the experimental plant. Lettuce seeds were sown in a seeding tray $(59 \times 30 \times 4.5 \mathrm{~cm}$; 118-plug tray filled with sponge blocks) and germinated in a nursery greenhouse maintained at $20 \pm 5^{\circ} \mathrm{C}$ under natural day length on 19 March, 2019. After $20 \mathrm{~d}$, the seedlings were transplanted into three environmentally controlled mini-PFALs (SRG-Y, Lianshuo Instrument Inc., China) for treatment. The miniPFALs were outfitted with a light-emitting diode (LED) light source, light timers, a sterilizer, and a systematized heat sink device. When they had three true leaves, the seedlings were planted in plastic basins $(13-\mathrm{cm}$ diameter $\times$ 14-cm height) at a density of one plant per basin. The plastic basins were filled with a modified Hoagland nutrient solution (Hoagland and Arnon 1950). The EC and $\mathrm{pH}$ of the nutrient solution were adjusted to $1.6 \mathrm{dS} \mathrm{m}^{-1}$ and 6.0 , respectively. Solution was added every second or third day to maintain the EC and $\mathrm{pH}$. Red and blue LED lamps (WEN-T8H, WEGA Plant Lighting Company, China) were used as light sources $(\mathrm{R}: \mathrm{B}=83: 17 \%)$. The energy aggregation areas of the blue and red lights in the spectra were approximately at 457 and $632 \mathrm{~nm}$, respectively. These two spectral regions are crucial for plant growth and nutritional quality (Landi et al. 2020). A PPFD of $250 \mu \mathrm{mol} \mathrm{m} \mathrm{m}^{-2} \mathrm{~s}^{-1}$, relative humidity (of air) of $60-70 \%$, and $\mathrm{CO}_{2}$ concentration of $400 \pm 50$ ppm were maintained throughout the experiments.

Experimental design: Experiments were arranged as follows: three light/dark cycles of 12/12 h (C12), 6/6 $\mathrm{h}$ (C6), and $3 / 3 \mathrm{~h}$ (C3) were set, and the plants were subjected to the treatments for $30 \mathrm{~d}$ after transplanting. Each light/dark cycle treatment contained 18 samples. The plants were rearranged randomly every second or third day to avoid positional effects within the mini-PFALs.

Light-response curves: An open-flow gas exchange system (LI-6400XT, Li-Cor, Lincoln, NE, USA) with an integrated fluorescence leaf chamber (LI-6400-40, Li-Cor, Lincoln, NE, USA) was used to simultaneously measure leaf fluorescence and gas exchange. To avoid the effect of environmental fluctuations on gas-exchange measurements, all measurements were taken in an artificial climatic chamber with an air temperature of $24 \pm 1^{\circ} \mathrm{C}$, a PPFD at the leaf surface of $750 \pm 50 \mu \mathrm{mol} \mathrm{m} \mathrm{m}^{-2} \mathrm{~s}^{-1}$, and a relative humidity of $60-70 \%$. LED arrays ( $K W-Z W D 06-T 8$, Kingwua Bright Inc., China) were used as light sources in the climatic chamber. Each lettuce sample exposed to light conditions in mini-PFALs for more than $1 \mathrm{~h}$ was sequentially moved into the artificial climatic chamber for measurement. The measurements were completed between 08:30 and 16:30 h. To minimize leaf position and age effects, the measurements were taken on the upper six fully expanded leaves after the plants had been acclimated to the room for approximately $30 \mathrm{~min}$. Three plants were used 
per treatment for the measurements. Before generating the light-response curve, the Chl content of the leaf was measured via the SPAD value, which was determined using a portable Chl meter (SPAD-502, Konica Minolta, Osaka, Japan). When full photoinduction of the lettuce plants was complete, an automatic program of light-response curves was run to measure the change in gas-exchange rate with a varied PPFD. The level of the PPFD was varied in the following order: 1,$200 ; 1,000 ; 800,600,500,350,200$, $150,100,80,50,0 \mu \mathrm{mol} \mathrm{m}{ }^{-2} \mathrm{~s}^{-1}$. Within the Li-Cor leaf chamber, the ambient $\mathrm{CO}_{2}$ concentration was adjusted to $400 \mu \mathrm{mol} \mathrm{s}^{-1}$ with a $\mathrm{CO}_{2}$ injection system, leaf temperature was maintained at $25^{\circ} \mathrm{C}$, PPFD was $800 \mu \mathrm{mol} \mathrm{m} \mathrm{m}^{-2} \mathrm{~s}^{-1}$ with a 10:90 blue:red light, leaf-to-air vapor pressure deficit (VPD) was between 1.1 and $1.4 \mathrm{kPa}$, and the flow rate was $300 \mu \mathrm{mol} \mathrm{s}{ }^{-1}$. The light-response curves were modeled by fitting modified rectangular hyperbolas to the data as described by following formula (Ye and Yu 2008):

$$
P_{\mathrm{N}}=\alpha \frac{1-\beta \times \text { PPFD }}{1+\gamma \times \text { PPFD }} \text { PPFD }-R_{\mathrm{D}}
$$

where $P_{\mathrm{N}}$ is the net photosynthetic rate, $\alpha$ is the initial slope or apparent photosynthetic quantum yield [i.e., the apparent quantum efficiency (AQY)], $\beta$ and $\gamma$ are constants independent of the PPFDs (dimensionless), and $R_{\mathrm{D}}$ is the dark respiration rate. The light-saturation point (LSP), light-compensation point (LCP), and $P_{\mathrm{Nmax}}$ were given by following formulae:

$$
\begin{aligned}
& P_{\text {Nmax }}=\alpha\left(\frac{\sqrt{\beta+\gamma}-\sqrt{\beta}}{\gamma}\right)^{2}-R_{\mathrm{D}} \\
& \mathrm{LSP}=\frac{\sqrt{(\beta+\gamma) / \beta}-1}{\gamma}
\end{aligned}
$$

$$
\mathrm{LCP}=\frac{\alpha-\gamma \beta-\sqrt{\left(\gamma R_{\mathrm{D}}-\mathrm{a}\right)^{2}-4 \alpha \beta R_{\mathrm{D}}}}{2 \alpha \beta}
$$

$\mathrm{CO}_{2}$-response curves: To estimate the relationship between the $P_{\mathrm{N}}$ and the intercellular $\mathrm{CO}_{2}$ concentration $\left(C_{\mathrm{i}}\right)$, $\mathrm{CO}_{2}$-response curves were generated. The temperature, PPFD, and $\mathrm{CO}_{2}$ concentration in the leaf chamber were adjusted to $25^{\circ} \mathrm{C}, 800 \mu \mathrm{mol} \mathrm{m}{ }^{-2} \mathrm{~s}^{-1}$, and $400 \mathrm{mmol} \mathrm{mol}^{-1}$, respectively. Measurements were taken to construct a $\mathrm{CO}_{2}$-response curve by adjusting the ambient $\mathrm{CO}_{2}$ concentration to $400,300,200,100,50,400,400,500$, 600,$800 ; 1,000 ; 1,200$; and $1,500 \mathrm{mmol} \mathrm{mol}^{-1}$. The $\mathrm{CO}_{2}$-response curves were obtained by fitting the data to a modified rectangular hyperbola (Ye and Yu 2009).

$$
P_{\mathrm{N}}=J \frac{1-\theta \times C_{\mathrm{i}}}{1+\omega \times C_{\mathrm{i}}} C_{\mathrm{i}}-R_{\mathrm{P}}
$$

where $J$ is the initial slope [i.e., initial carboxylation efficiency (CE)], $\theta$ and $\omega$ are constants (dimensionless), $R_{\mathrm{P}}$ is the photorespiration rate. The $\mathrm{CO}_{2}$-saturation point $\left(C_{\text {isat }}\right), \mathrm{CO}_{2}$-compensation point $\left(\Gamma^{*}\right)$, and $\mathrm{CO}_{2}$-saturated net photosynthetic rate $\left(A_{\mathrm{Nmax}}\right)$ were given by following formulae:

$$
C_{\text {isat }}=\frac{\sqrt{(\theta+\omega) / \theta}-1}{\omega}
$$

$\Gamma^{*}=\frac{J-\omega \theta-\sqrt{\left(\omega R_{\mathrm{P}}-J\right)^{2}-4 J \theta R_{\mathrm{P}}}}{2 J \theta}$

$$
A_{\mathrm{N} \max }=J\left(\frac{\sqrt{\theta+\omega}-\sqrt{\theta}}{\omega}\right)^{2}-R \mathrm{P}
$$

Fluorescence parameters: The Chl fluorescence parameters of lettuce under different light cycles were determined using the $L i-6400 X T$ gas-exchange system from 19:00-21:00 $\mathrm{h}$. The variables measured in the experiment included the minimal fluorescence yield of the darkadapted state $\left(\mathrm{F}_{0}\right)$, maximal fluorescence yield of the dark-adapted state $\left(\mathrm{F}_{\mathrm{m}}\right)$, variable fluorescence $\left(\mathrm{F}_{\mathrm{v}}\right)$, and maximal quantum yield of PSII photochemistry $\left(\mathrm{F}_{\mathrm{v}} / \mathrm{F}_{\mathrm{m}}\right)$. The measured blade and repetition number were consistent with the measured light-response curve.

Growth and biomass measurements: At the end of the experimental period, plant height, canopy area, LA per plant, leaf shape ratio, and specific leaf area (SLA, projected total leaf area per unit leaf dry mass) were determined. Photographs were taken of the top and side of each plant, and image processing was conducted using ImageJ software (National Institutes of Health, Bethesda, MD, USA) to obtain the plant height and canopy area. The LA and leaf shape ratio were obtained by scanning the leaves of each plant using a $L A 2400$ scanner. The leaf shape ratio was calculated as the ratio of leaf length to leaf width. Images were then acquired using the WinFOLIA software (Regent Instruments Inc., Quebec). The leaves and roots were separated and weighed collectively to determine the fresh mass (FM) using an electronic analytical balance with an accuracy of $0.1 \mathrm{mg}$. The dry mass (DM) of the leaves and roots was obtained by first drying them in an oven at $105^{\circ} \mathrm{C}$ for $1 \mathrm{~h}$ and then drying at $80^{\circ} \mathrm{C}$ for another $48 \mathrm{~h}$. The root/shoot ratio was estimated as the ratio of below- to aboveground DM.

Statistical analysis: Results are expressed as the mean \pm SD of three replicates in each of three individuals. The data were analyzed using a one-way analysis of variance (ANOVA) and a multiple comparisons test using SPSS 20 software. Multiple comparisons between treatment means were conducted using the least significant difference (LSD) test at $p<0.05$. Pearson's analysis (two-tailed) was used to evaluate the correlations between the SPAD and $\mathrm{F}_{0}$. All the model parameters were evaluated with a nonlinear regression using OriginPro 8 software. Graphs and tables were constructed using Microsoft Excel 2013.

\section{Results}

Leaf gas exchange: As shown in Fig. 1, the curves of the $P_{\mathrm{N}}$ showed parallel changes under different light cycles. In the range of $0-200 \mu \mathrm{mol}\left(\right.$ photon) $\mathrm{m}^{-2} \mathrm{~s}^{-1}$, there was no 
significant difference in the $P_{\mathrm{N}}$ between the three light/dark cycles treatments. Above $200 \mu \mathrm{mol}$ (photon) $\mathrm{m}^{-2} \mathrm{~s}^{-1}$, leaves in the $\mathrm{C} 12$ treatment showed a higher $P_{\mathrm{N}}$ at all PPFDs. The $P_{\mathrm{N}}$ value was the highest in the $\mathrm{C} 12$ treatment followed by the $\mathrm{C} 6$ treatment, and these two light/dark cycles had a similar effect on the light-use efficiency of lettuce plants. The $P_{\mathrm{N}}$ in the $\mathrm{C} 3$ treatment was significantly lower than that in the other light/dark cycles. The light-response curves were well fitted by the modified rectangular hyperbolic model as indicated by the $R^{2}$ values, which were greater than 0.998 (Table 1). There was no significant difference between the AQY in all light cycles. Lettuce in the C12 and C6 treatments had a higher and significantly different $P_{\text {Nmax }}$ compared with the C3 treatment. The $P_{\text {Nmax }}$ in the C6 and C12 treatments were 44 and 60\% higher than that in the $\mathrm{C} 3$ treatment, respectively. A similar pattern was observed in $R_{\mathrm{D}}$ values, which were 18 and $30 \%$ higher in the leaves under the C6 and C12 treatments compared to the leaves under the $\mathrm{C} 3$ treatment. The highest LSP and LCP occurred in the $\mathrm{C} 12$ treatment and were significantly higher than that in the $\mathrm{C} 6$ and $\mathrm{C} 3$ treatments.

$\mathrm{CO}_{2}$-response curve: There was a significant difference in the $P_{\mathrm{N}}$ values with regard to the different light/dark cycles applied. The $P_{\mathrm{N}}$ value was the highest in the $\mathrm{C} 12$ treatment followed the C6 and C3 treatments (Fig. 2). The $R^{2}$ values in these three treatments were all greater than 0.991 , which

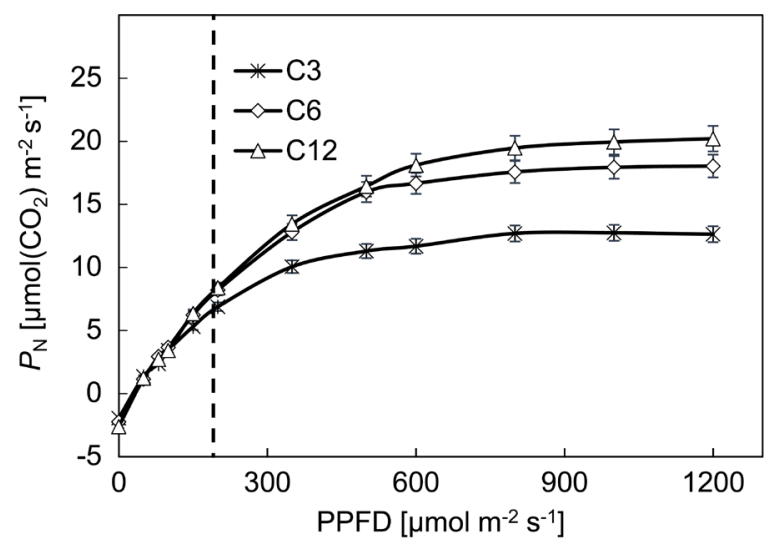

Fig. 1. Light response curve of lettuce under the light/dark cycles of $\mathrm{C} 3, \mathrm{C} 6$, and C12. $P_{\mathrm{N}}-$ net photosynthetic rate. Dashed vertical line indicates PPFD value of $200 \mu \mathrm{mol} \mathrm{m}^{-2} \mathrm{~s}^{-1}$. Mean values with standard error of mean $(n=3)$. indicates that the $\mathrm{CO}_{2}$-response curves were well-fitted by the modified rectangular hyperbolic model (Table 2). The $A_{\text {Nmax }}$ in the $\mathrm{C} 12$ treatment was significantly higher than that in the $\mathrm{C} 6$ and $\mathrm{C} 3$ treatments. There was no significant difference in the $A_{\mathrm{Nmax}}$ between the $\mathrm{C} 6$ and $\mathrm{C} 3$ treatments. The CE varied significantly with the light/dark cycle treatment. The $\mathrm{CE}$ was the highest in the $\mathrm{C} 12$ treatment and the lowest in the $\mathrm{C} 3$ treatment. In contrast, the change in $\Gamma^{*}$ was significantly higher in the $\mathrm{C} 3$ treatment than that in the $\mathrm{C} 12$ treatment. The $C_{\text {isat }}$ decreased as the light cycle prolonged, however, there was no significant difference between the $C_{\text {isat }}$ values under different light/dark cycles. The $R_{\mathrm{P}}$ was significantly different between the different light/dark cycle treatments and showed an increase with the lengthening of the light cycle. The $R_{\mathrm{P}}$ increased by 23 and $53 \%$ for the $\mathrm{C} 6$ and $\mathrm{C} 12$ treatments, respectively, compared to the $\mathrm{C} 3$ treatment.

Fluorescence parameters: As the length of the light cycle increased, the SPAD increased and reached its highest level in the $\mathrm{C} 12$ treatment (Table 3). The lowest SPAD was observed in the $\mathrm{C} 3$ treatment, but did not differ significantly from that observed in the C6 treatment. Similarly as the SPAD, the $F_{o}$ and $F_{m}$ increased with the lengthening of the light cycle and reached their highest levels in the $\mathrm{C} 12$ treatment. There was no significant difference in the $\mathrm{F}_{0}$ between the $\mathrm{C} 12$ and $\mathrm{C} 6$ treatments. The $\mathrm{F}_{\mathrm{m}}$ value in the C12 treatment was almost 15 and 24\% higher compared to the $\mathrm{C} 6$ and $\mathrm{C} 3$ treatments, respectively. There was no significant difference in $\mathrm{F}_{\mathrm{v}} / \mathrm{F}_{\mathrm{m}}$ between the three light/ dark cycles. The $\mathrm{F}_{\mathrm{v}} / \mathrm{F}_{\mathrm{m}}$ values in all light cycle treatments fluctuated within range of $0.81-0.83$.

Plant performance: The growth of lettuce plants was significantly affected by light/dark cycles (Table 4). As the length of the light cycle increased, LA and fresh shoot mass increased significantly. LA increased by 11 and $31 \%$ for the C6 and C12 treatments, respectively, compared to the $\mathrm{C} 3$ treatment. Fresh shoot mass increased by 31 and $60 \%$ for the $\mathrm{C} 6$ and $\mathrm{C} 12$ treatments, respectively, compared to the $\mathrm{C} 3$ treatment. Plant height, canopy area, root FM, shoot DM, and root DM were the highest in the $\mathrm{C} 12$ treatment and the lowest in the $\mathrm{C} 3$ treatment. The root/ shoot ratio and SLA were the highest in the $\mathrm{C} 3$ treatment and were significantly higher than that in the C6 and C12 treatments. No significant difference in the root/shoot ratio was observed between the $\mathrm{C} 12$ and $\mathrm{C} 6$ treatments.

Table 1. Characteristic parameters of the light response curve for lettuce under the light/dark cycles of C3, C6, and C12. AQY - apparent quantum efficiency; $P_{\mathrm{Nmax}}$ - light-saturated net photosynthetic rate; LSP - light-saturation point; LCP - light-compensation point; $R^{2}$ - coefficient of determination; $R_{\mathrm{D}}$ - dark respiration rate. Different lowercase letters indicate significant difference at $p<0.05$ in the LSD test. The results are presented as the mean $\pm \mathrm{SD}(n=3)$.

\begin{tabular}{lllllll}
\hline $\begin{array}{l}\text { Treat- } \\
\text { ment }\end{array}$ & $\begin{array}{l}\mathrm{AQY} \\
{\left[\mu \mathrm{mol}\left(\mathrm{CO}_{2}\right) \mu \mathrm{mol}^{-1}(\text { photon })\right]}\end{array}$ & $\begin{array}{l}P_{\mathrm{Nmax}} \\
{\left[\mu \mathrm{mol}\left(\mathrm{CO}_{2}\right) \mathrm{m}^{-2} \mathrm{~s}^{-1}\right]}\end{array}$ & $\begin{array}{l}\mathrm{LSP} \\
{\left[\mu \mathrm{mol}\left(\mathrm{CO}_{2}\right) \mathrm{m}^{-2} \mathrm{~s}^{-1}\right]}\end{array}$ & $\begin{array}{l}\mathrm{LCP} \\
{\left[\mu \mathrm{mol}\left(\mathrm{CO}_{2}\right) \mathrm{m}^{-2} \mathrm{~s}^{-1}\right]}\end{array}$ & $\begin{array}{l}R_{\mathrm{D}} \\
{\left[\mu \mathrm{mol}\left(\mathrm{CO}_{2}\right) \mathrm{m}^{-2} \mathrm{~s}^{-1}\right]}\end{array}$ \\
\hline $\mathrm{C} 12$ & $0.074 \pm 0.001^{\mathrm{a}}$ & $20.223 \pm 0.451^{\mathrm{a}}$ & $1,055.917 \pm 23.187^{\mathrm{a}}$ & $36.237 \pm 0.910^{\mathrm{a}}$ & $2.540 \pm 0.031^{\mathrm{a}}$ & 0.999 \\
$\mathrm{C} 6$ & $0.074 \pm 0.000^{\mathrm{a}}$ & $18.167 \pm 1.448^{\mathrm{a}}$ & $969.864 \pm 5.955^{\mathrm{b}}$ & $32.991 \pm 1.471^{\mathrm{b}}$ & $2.304 \pm 0.127^{\mathrm{a}}$ & 0.999 \\
$\mathrm{C} 3$ & $0.071 \pm 0.001^{\mathrm{a}}$ & $12.653 \pm 1.030^{\mathrm{b}}$ & $928.788 \pm 8.775^{\mathrm{b}}$ & $30.183 \pm 0.102^{\mathrm{b}}$ & $1.959 \pm 0.028^{\mathrm{b}}$ & 0.998 \\
\hline
\end{tabular}




\section{Discussion}

The photosynthetic characteristics exhibited contrasting trends in the photosynthetic capacity of lettuce in response to changes in the light/dark cycle in the mini-PFAL system. Among the three light/dark cycles, the lettuce

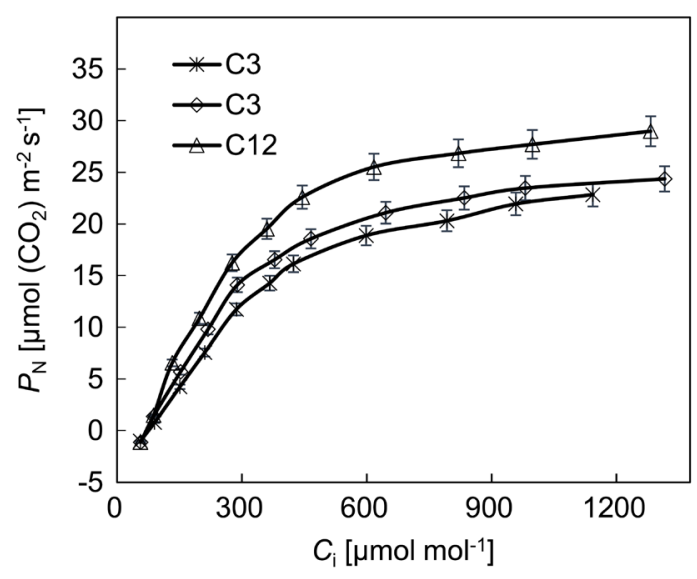

Fig. 2. $\mathrm{CO}_{2}$-response curve of lettuce under the light/dark cycles of C3, C6, and C12. $P_{\mathrm{N}}-$ net photosynthetic rate; $C_{\mathrm{i}}$-intercellular $\mathrm{CO}_{2}$ concentration. Mean values with standard error of mean $(n=3)$. grown in the longer light cycle had higher $P_{\mathrm{Nmax}}$, LSP, and $P_{\mathrm{N}}$ values in the light-response curve, which demonstrates that lettuce plants under a longer light cycle had a greater photosynthetic capacity and could adapt to higher light intensity conditions. The reason for this relationship may be that leaf photosynthesis exhibits a delayed response in reaching its maximal photosynthetic rate when plants are illuminated after a prolonged exposure to darkness (Jun and Hong 2002). This phenomenon of photosynthesis lag is due to the photoactive opening of stomata, the accumulation of metabolites to a sufficient level and light-activation of stromal enzymes require a prior process. The prolonged light cycle actually reduced the proportion of photosynthetic lag time to total photosynthetic time. The longer light cycle provided more time for plant photoaccumulation. In addition, the previous studies have shown that the plant circadian rhythm is involved in coordinating responses of physiological and developmental processes, such as photosynthesis, respiration, and metabolism (Greenham and McClung 2015, Song et al. 2015). Circadian rhythm enables plants to fix more carbon, contain more Chl during the photoperiod and maximize photosynthetic rates, providing a competitive advantage (Dodd et al. 2005). According to the photosynthetic rates under all treatments, we observed that $\mathrm{C} 12$ and C6 treatments significantly increased photosynthetic capacity of leaves compared to C3. This might be due to that the plant circadian rhythms

Table 2. Characteristic parameters of the $\mathrm{CO}_{2}$-response curve for lettuce under the light/dark cycles of $\mathrm{C} 3, \mathrm{C} 6$, and $\mathrm{C} 12$. $\mathrm{CE}$ - initial carboxylation efficiency; $A_{\mathrm{Nmax}}-\mathrm{CO}_{2}$-saturated net photosynthetic rate; $C_{\text {isat }}-\mathrm{CO}_{2}$-saturation point; $\Gamma^{*}-\mathrm{CO}_{2}$-compensation point; $R^{2}-$ coefficient of determination; $R_{\mathrm{P}}$ - photorespiration rate. Different lowercase letters indicate significant difference at $p<0.05$ in the LSD test. The results are presented as the mean $\pm \mathrm{SD}(n=3)$.

\begin{tabular}{lllllll}
\hline Treatment & $\mathrm{CE}\left[\mathrm{mol}\left(\mathrm{CO}_{2}\right) \mathrm{m}^{-2} \mathrm{~s}^{-1}\right]$ & $A_{\mathrm{Nmax}}\left[\mu \mathrm{mol}\left(\mathrm{CO}_{2}\right) \mathrm{m}^{-2} \mathrm{~s}^{-1}\right]$ & $C_{\text {isat }}\left[\mu \mathrm{mol} \mathrm{mol}{ }^{-1}\right]$ & $\Gamma^{*}\left[\mu \mathrm{mol} \mathrm{mol}^{-1}\right]$ & $R_{\mathrm{P}}\left[\mu \mathrm{mol}\left(\mathrm{CO}_{2}\right) \mathrm{m}^{-2} \mathrm{~s}^{-1}\right]$ & $R^{2}$ \\
\hline $\mathrm{C} 12$ & $0.183 \pm 0.019^{\mathrm{a}}$ & $28.528 \pm 2.165^{\mathrm{a}}$ & $1,184.096 \pm 27.215^{\mathrm{a}}$ & $69.700 \pm 2.656^{\mathrm{b}}$ & $10.418 \pm 0.381^{\mathrm{a}}$ & 0.996 \\
$\mathrm{C} 6$ & $0.141 \pm 0.004^{\mathrm{b}}$ & $23.902 \pm 0.416^{\mathrm{b}}$ & $1,235.669 \pm 3.649^{\mathrm{a}}$ & $71.751 \pm 0.745^{\mathrm{ab}}$ & $8.325 \pm 1.566^{\mathrm{b}}$ & 0.997 \\
$\mathrm{C} 3$ & $0.103 \pm 0.004^{\mathrm{c}}$ & $22.624 \pm 0.752^{\mathrm{b}}$ & $1,245.648 \pm 54.580^{\mathrm{a}}$ & $76.387 \pm 1.029^{\mathrm{a}}$ & $6.795 \pm 0.344^{\mathrm{c}}$ & 0.991 \\
\hline
\end{tabular}

Table 3. SPAD values and fluorescence parameters for lettuce under the light/dark cycles of C3, C6, and C12. $\mathrm{F}_{0}-$ minimal fluorescence yield of the dark-adapted state; $F_{m}$ - maximal fluorescence yield of the dark-adapted state; $F_{v}$ - variable fluorescence; $F_{v} / F_{m}-$ maximal quantum yield of PSII photochemistry; SPAD - unitless value obtained with the SPAD-502 chlorophyll meter. Different lowercase letters indicate significant difference at $p<0.05$ in the LSD test. The results are presented as the mean $\pm \operatorname{SD}(n=3)$.

\begin{tabular}{lllll}
\hline Treatment & SPAD & $\mathrm{F}_{0}$ & $\mathrm{~F}_{\mathrm{m}}$ & $\mathrm{F}_{\mathrm{v}} / \mathrm{F}_{\mathrm{m}}$ \\
\hline $\mathrm{C} 12$ & $27.58 \pm 0.05^{\mathrm{a}}$ & $151.13 \pm 7.84^{\mathrm{a}}$ & $881.27 \pm 50.40^{\mathrm{a}}$ & $0.83 \pm 0.00^{\mathrm{a}}$ \\
$\mathrm{C} 6$ & $21.63 \pm 0.35^{\mathrm{b}}$ & $142.70 \pm 5.31^{\mathrm{a}}$ & $769.27 \pm 19.63^{\mathrm{b}}$ & $0.81 \pm 0.01^{\mathrm{a}}$ \\
$\mathrm{C} 3$ & $20.22 \pm 0.43^{\mathrm{b}}$ & $126.23 \pm 4.42^{\mathrm{b}}$ & $711.60 \pm 19.51^{\mathrm{b}}$ & $0.82 \pm 0.00^{\mathrm{a}}$ \\
\hline
\end{tabular}

Table 4. Effect of light/dark cycles on the growth and development of lettuce. DM - dry mass; FM - fresh mass; SLA - specific leaf area. Different lowercase letters indicate significant difference at $p<0.05$ in the LSD test. The results are presented as the mean $\pm \operatorname{SD}(n=3)$.

\begin{tabular}{|c|c|c|c|c|c|c|c|c|c|}
\hline $\begin{array}{l}\text { Treat- } \\
\text { ment }\end{array}$ & $\begin{array}{l}\text { Plant height } \\
{[\mathrm{cm}]}\end{array}$ & $\begin{array}{l}\text { Leaf area } \\
{\left[\mathrm{cm}^{2}\right]}\end{array}$ & $\begin{array}{l}\text { Canopy area } \\
{\left[\mathrm{cm}^{2}\right]}\end{array}$ & $\begin{array}{l}\text { Shoot FM } \\
{[\mathrm{g}]}\end{array}$ & $\begin{array}{l}\text { Root FM } \\
{[\mathrm{g}]}\end{array}$ & $\begin{array}{l}\text { Shoot DM } \\
{[\mathrm{g}]}\end{array}$ & $\begin{array}{l}\text { Root DM } \\
{[\mathrm{g}]}\end{array}$ & $\begin{array}{l}\text { Root/shoot } \\
\text { ratio }\end{array}$ & $\begin{array}{l}\text { SLA } \\
{\left[\mathrm{m}^{2} \mathrm{~kg}^{-1}(\mathrm{DM})\right]}\end{array}$ \\
\hline 12 & 8.55 & 602. & a 152.6 & $43.14 \pm 0.69^{\mathrm{a}}$ & $3.91 \pm 0.08^{\mathrm{a}}$ & 2.42 & 0.29 & 0.1 & $.94^{\mathrm{b}}$ \\
\hline C6 & $7.76 \pm 0.14^{\mathrm{ab}}$ & $512.94 \pm 3.53^{b}$ & $143.23 \pm$ & $35.22 \pm 0.89^{b}$ & $3.60=$ & 1.99 & 0.26 & 0.13 & $.28^{\mathrm{b}}$ \\
\hline $\mathrm{C} 3$ & $7.00 \pm 0.64^{b}$ & $460.34 \pm 9.28^{c}$ & $138.83 \pm 5.54^{b}$ & $26.91 \pm 0.94^{c}$ & $3.45 \pm 0.19^{b}$ & $1.62 \pm 0.08^{b}$ & $0.25 \pm 0.01^{\mathrm{a}}$ & $0.15 \pm 0.01^{\mathrm{a}}$ & $28.50 \pm 0.80^{\mathrm{a}}$ \\
\hline
\end{tabular}


in $\mathrm{C} 12$ and $\mathrm{C} 6$ were maintained more stable than that in C3, which maximized photosynthetic rates despite the environments changed. Plants no longer accumulate organic matter when the light intensity is lower than the LCP. The $R_{\mathrm{D}}$ value reflects the plant's consumption of photosynthetic products. Both the LCP and $R_{\mathrm{D}}$ were enhanced by the $\mathrm{C} 12$ treatment compared to the $\mathrm{C} 6$ and $\mathrm{C} 3$ treatments, implying that the long light cycle increased the consumption of photosynthetic products, resulting in a relatively inefficient use of resources (Zhang et al. 2015). There was no significant difference in the AQY between the three light cycles, indicating that the influence of light/dark cycles on the ability of lettuce to use low light energy was not notable. Leaf photosynthesis measured at different $\mathrm{CO}_{2}$ concentrations significantly varied with light/dark cycles. The maximum $A_{\mathrm{Nmax}}$ and $P_{\mathrm{N}}$ values of the $\mathrm{CO}_{2}$-response curve of lettuce under the $\mathrm{C} 12$ treatment showed that lettuce was more adaptable to a high $\mathrm{CO}_{2}$ environment under the longer light cycle. The $\mathrm{CE}$ is a measure of the activity and efficiency of Rubisco. A higher $\mathrm{CE}$ value corresponds to a more complete carboxylation efficiency during photosynthesis (Liu et al. 2014). The CE was significantly enhanced under the longer light cycle, which shows that lettuce plants had more efficient $\mathrm{CO}_{2}$ uptake under long light cycle conditions. In addition, the $\Gamma^{*}$ of lettuce decreased significantly as the light cycle increased, implying that lettuce plants in the longer light cycle treatments had a higher light-use efficiency under a low $\mathrm{CO}_{2}$ environment. The peak $R_{\mathrm{P}}$ value of lettuce in the $\mathrm{C} 12$ treatment indicates that the long light cycle resulted in a high respiration rate in Lactuca sativa.

Leaf Chl content is one of the most important factors determining leaf photosynthetic capability and dry matter production. The leaf SPAD value is considered a useful indicator of leaf Chl content (Loh et al. 2002, Ling et al. 2011). The lower SPAD that we observed in the C3 and C6 treatments may partially explain the lower photosynthetic rates and dry shoot masses found in the plant leaves from those two treatments. The marked increase in SPAD in the C12 treatment demonstrates the plant's ability to enhance the light-harvesting capacity under long light cycle conditions. $\mathrm{F}_{\mathrm{v}} / \mathrm{F}_{\mathrm{m}}$ value indicates the PSII maximum light conversion efficiency. In healthy organisms, the $F_{v} / F_{m}$ value is approximately $0.8-0.84$ in most $C_{3}$ plant species, but the value decreases significantly when plants are exposed to stress (Oxborough and Baker 1997, Baker 2008, Kalaji et al. 2014). The $F_{\mathrm{v}} / \mathrm{F}_{\mathrm{m}}$ values in all treatments were all above 0.8 , indicating that different light cycle treatments would not cause loss of photosynthetic activity and poten-tial efficiency of PSII. Hence, the differences in the $\mathrm{F}_{0}$ value or $\mathrm{F}_{\mathrm{m}}$ value were not caused by any reversible inactivation of the PSII reaction center. It has been previously suggested that $\mathrm{F}_{0}$ value was mainly determined by the difference in Chl content in leaves (Strasser et al. 2004, Fu et al. 2012). Among all treatments, a positive correlation was observed between the $\mathrm{F}_{0}$ value and the SPAD (Pearson's $r=0.769, p<0.05$ ). A maximum $\mathrm{F}_{0}$ value was found in $\mathrm{C} 12$ treatment. It might be hypothesized that the longer light cycle conditions resulted in the higher Chl content of plant leaves, the more light energy was absorbed, and so higher $\mathrm{F}_{0}$ values were obtained after dark adaptation. However, the experimental results showed that although there was no significant difference in the SPAD under $\mathrm{C} 6$ and $\mathrm{C} 3$ treatments, the $\mathrm{F}_{0}$ values under $\mathrm{C} 6$ treatment were significantly higher than those under $\mathrm{C} 3$ treatment. Therefore, other mechanisms are presumably responsible for the variation in $\mathrm{F}_{0}$ observed in this study. According to several authors, this parameter was associated with the changes of the antenna size and the contribution of fluorescence originating from PSI (Dinç et al. 2012, Brestič et al. 2015). More likely, the antenna size and the PSI fluoresence could be maintained at higher levels under $\mathrm{C} 6$ treatment than those under $\mathrm{C} 3$, resulting in higher $\mathrm{F}_{0}$ values under $\mathrm{C} 6$. The $\mathrm{F}_{\mathrm{m}}$ denotes the maximum fluorescence yield in dark-adapted leaves, and reflects electron transfer through the PSII reaction center (Baruffo and Tretiach 2007). A block on the donor side of PSII is generally correlated with quenching of $\mathrm{F}_{\mathrm{m}}$ due to the lack of electrons available to provide for the accumulation of the primary plastoquinone acceptor (Govindjee 1995). Similar conclusions are referred here. As the light cycle increased, the $\mathrm{F}_{\mathrm{m}}$ increased significantly and reached its maximum in the $\mathrm{C} 12$ treatment. The increase in $\mathrm{F}_{\mathrm{m}}$ values was probably due to the increase of electron accumulation on the donor side of PSII by the long light cycle.

Although the long light cycle increased the consumption of photosynthetic products, the fresh shoot mass, fresh root mass, dry shoot mass, and root mass increased with an increase in the length of the light cycle. This is consistent with the findings of Park et al. (2012) in lettuce plants. Compared to values in other light cycles, the plant height, LA, and canopy area increased significantly when the light cycle reached the $\mathrm{C} 12$ levels. This shows that the long light cycle was beneficial for lettuce growth under low light intensity. However, the root/shoot ratio decreased with an increase in length of the light cycle, which shows that more mass was allocated to aboveground tissues under long light cycle conditions. The SLA reflects the LA for light capture per unit mass. A high SLA was observed in plants grown in the C3 treatment. For the sunflower, Tardieu et al. (1999) found that the SLA increases if the environmental conditions suppress the expansion rate more strongly than the photosynthetic rate and vice versa. The current findings indicated a larger effect of short light cycle on leaf expansion than dry matter accumulation. As previously reported, the shortened light cycle made the leaves compact and rounder (Hang et al. 2019). Thus, the long light cycle in the mini-PFAL system favored higher biomass accumulation and was more likely to cause an increase in the carbohydrates used for physiological metabolism and growth.

Light/dark cycles have a significant effect on the effective absorption, transmission, and transformation of light energy in lettuce plants. Lettuce responds to changes in light/dark cycles by altering its photosynthetic physiology, allocation of resources and morphology. As indicated by $\mathrm{F}_{\mathrm{v}} / \mathrm{F}_{\mathrm{m}}$ values, the lettuce plants grew without stress under the three light/dark cycles. However, the variety of $F_{m}$ values indicated that the lengthened light cycle had a positive effect on electron transfer potential on the donor 
side of PSII. In addition, the different light/dark cycles had a significant effect on lettuce photosynthesis and growth. The prolonged light cycle led to an increase in photosynthetic capacity and $\mathrm{CO}_{2}$-uptake efficiency, which significantly enhanced the growth rate of lettuce. When the lettuce plants grew under the $\mathrm{C} 12$ conditions, plant height, LA, leaf FM, and leaf DM were maximized. The root/shoot ratio and the SLA increased as the light cycle was shortened. The shortened light cycle led to more mass being allocated to the root and to more compact leaves. The results showed that if light energy and $\mathrm{CO}_{2}$ in mini-PFALs are to be fully utilized to achieve high yields, a long light cycle under low light conditions is a wise choice. However, given the time-specific charges in some areas, the energy consumption costs under different light and dark cycles should be calculated according to the local electricity tariff standards. Further studies are needed to determine the appropriate light and dark cycles by comparing the input/ output ratio of the lettuce product.

\section{References}

Abidi F., Girault T., Douillet O. et al.: Blue light effects on rose photosynthesis and photomorphogenesis. - Plant Biol. 15: 67-74, 2012.

Ali M.B., Khandaker L., Oba S.: Comparative study on functional components, antioxidant activity and color parameters of selected colored leafy vegetables as affected by photoperiods. - J. Food Agric. Environ. 7: 392-398, 2009.

Avola G., Cavallaro V., Patanè C., Riggi E.: Gas exchange and photosynthetic water use efficiency in response to light, $\mathrm{CO}_{2}$ concentration and temperature in Vicia faba. - J. Plant Physiol. 165: 796-804, 2008.

Baker N.R.: Chlorophyll fluorescence: a probe of photosynthesis in vivo. - Annu. Rev. Plant Biol. 59: 89-113, 2008.

Baruffo L., Tretiach M.: Seasonal variations of $F_{0}, F_{m}$, and $F_{v} / F_{m}$ in an epiphytic population of the lichen Punctelia subrudecta (Nyl.) Krog. - Lichenologist 39: 555-565, 2007.

Brestič M., Živčák M., Kunderlíková K. et al.: Low PSI content limits the photoprotection of PSI and PSII in early growth stages of chlorophyll $b$-deficient wheat mutant lines. Photosynth. Res. 125: 151-166, 2015.

Dai Y., Shen Z., Liu Y. et al.: Effects of shade treatments on the photosynthetic capacity, chlorophyll fluorescence, and chlorophyll content of Tetrastigma hemsleyanum Diels et Gilg. - Environ. Exp. Bot. 65: 177-182, 2009.

Dinç E., Ceppi M.G., Tóth S.Z. et al.: The chl $a$ fluorescence intensity is remarkably insensitive to changes in the chlorophyll content of the leaf as long as the chl $a / b$ ratio remains unaffected. - BBA-Bioenergetics 1817: 770-779, 2012.

Dodd A.N., Salathia N., Hall A. et al.: Plant circadian clocks increase photosynthesis, growth, survival, and competitive advantage. - Science 309: 630-633, 2005.

$\mathrm{Fu}$ W., Li P., Wu Y.: Effects of different light intensities on chlorophyll fluorescence characteristics and yield in lettuce. Sci. Hortic.-Amsterdam 135: 45-51, 2012.

Gaudreau L., Charbonneau J.E., Vézina L.-P., Gosselin A.: Photoperiod and photosynthetic photon flux influence growth and quality of greenhouse-grown lettuce. - HortScience 29: 1285-1289, 1994.

Govindjee: Sixty-three years since Kautsky: Chlorophyll a fluorescence. - Aust. J. Plant Physiol. 22: 131-160, 1995.

Greenham K., McClung C.R.: Integrating circadian dynamics with physiological processes in plants. - Nat. Rev. Genet. 16:
598-610, 2015.

Hang T., Lu N., Takagaki M., Mao H.: Leaf area model based on thermal effectiveness and photosynthetically active radiation in lettuce grown in mini-plant factories under different light cycles. - Sci. Hortic.-Amsterdam 252: 113-120, 2019.

Hoagland D.R., Arnon D.I.: The Water-Culture Method for Growing Plants without Soil. Pp. 31. California Agricultural Experiment Station, Berkeley 1950.

Ishii M., Ito T., Maruo T. et al.: Plant growth and physiological characters of lettuce plants grown under artificial light of different irradiating cycles. - Environ. Control Biol. 33: 143-149, 1995.

Jun S.-S., Hong Y.-N.: Manifestation of a prolonged lag in the photosynthesis of heated spinach chloroplasts. - J. Plant Biol. 45: 37-43, 2002.

Kalaji H.M., Schansker G., Ladle R.J. et al.: Frequently asked questions about in vivo chlorophyll fluorescence: practical issues. - Photosynth. Res. 122: 121-158, 2014.

Kitaya Y., Niu G., Kozai T., Ohashi M.: Photosynthetic photon flux, photoperiod, and $\mathrm{CO}_{2}$ concentration affect growth and morphology of lettuce plug transplants. - HortScience 33: 988-991, 1998.

Koontz H., Prince R.: Effect of 16 and 24 hours daily radiation (light) on lettuce growth. - HortScience 21: 123-124, 1986.

Kozai T.: Plant factory in Japan - Current situation and perspectives. - Chron. Hortic. 53: 8-11, 2013a.

Kozai T.: Resource use efficiency of closed plant production system with artificial light: concept, estimation and application to plant factory. - P. Jpn. Acad. B-Phys. 89: 447-461, 2013b.

Kř́stková E., Doležalová I., Lebeda A. et al.: Description of morphological characters of lettuce (Lactuca sativa L.) genetic resources. - Hortic. Sci. 35: 113-129, 2008.

Landi M., Živčák M., Sytar O. et al.: Plasticity of photosynthetic processes and the accumulation of secondary metabolites in plants in response to monochromatic light environments: A review. - BBA-Bioenergetics 1861: 148131, 2020.

Li Q., Kubota C.: Effects of supplemental light quality on growth and phytochemicals of baby leaf lettuce. - Environ. Exp. Bot. 67: 59-64, 2009.

Lin K.-H., Huang M.-Y., Huang W.-D. et al.: The effects of red, blue, and white light-emitting diodes on the growth, development, and edible quality of hydroponically grown lettuce (Lactuca sativa L. var. capitata). - Sci. Hortic.Amsterdam 150: 86-91, 2013.

Ling Q., Huang W., Jarvis P.: Use of a SPAD-502 meter to measure leaf chlorophyll concentration in Arabidopsis thaliana. - Photosynth. Res. 107: 209-214, 2011.

Liu L., Wang Z., Zhao X. et al.: Effects of different photorespiration inhibitors on photosynthetic characteristics and berry quality of Vitis amurensis Rupr. - Can. J. Plant Sci. 95: 417-426, 2014.

Loh F.C.W., Grabosky J.C., Bassuk N.L.: Using the SPAD 502 meter to assess chlorophyll and nitrogen content of benjamin fig and cottonwood leaves. - HortTechnology 12: 682-686, 2002.

Miyagi A., Uchimiya H., Kawai-Yamada M.: Synergistic effects of light quality, carbon dioxide and nutrients on metabolite compositions of head lettuce under artificial growth conditions mimicking a plant factory. - Food Chem. 218: 561-568, 2017.

Noda H., Muraoka H., Washitani I.: Morphological and physiological acclimation responses to contrasting light and water regimes in Primula sieboldii. - Ecol. Res. 19: 331-340, 2004.

Oxborough K., Baker N.R.: An instrument capable of imaging chlorophyll $a$ fluorescence from intact leaves at very low irradiance and at cellular and subcellular levels of organization. - 
Plant Cell Environ. 20: 1473-1483, 1997.

Park J.E., Park Y.G., Jeong B.R., Hwang S.J.: [Growth and anthocyanin content of lettuce as affected by artificial light source and photoperiod in a closed-type plant production system.] - Korean J. Hortic. Sci. 30: 673-679, 2012. [In Korean]

Rascher U., Liebig M., Lüttge U.: Evaluation of instant lightresponse curves of chlorophyll fluorescence parameters obtained with a portable chlorophyll fluorometer on site in the field. - Plant Cell Environ. 23: 1397-1405, 2000.

Song Y.H., Shim J.S., Kinmonth-Schultz H.A., Imaizumi T.: Photoperiodic flowering: time measurement mechanisms in leaves. - Annu. Rev. Plant Biol. 66: 441-464, 2015.

Strasser R.J., Tsimilli-Michael M., Srivastava A.: Analysis of the chlorophyll a fluorescence transient. - In: Papageorgiou G.C., Govindjee (ed.): Chlorophyll a Fluorescence: A Signature of Photosynthesis. Advances in Photosynthesis and Respiration. Pp. 321-362. Springer, Dordrecht 2004.

Takagaki M., Hara H., Kozai T.: Micro- and Mini-PFALs for Improving the Quality of Life in Urban Areas. - In: Kozai T., Niu G., Takagaki M. (ed.): Plant Factory: An Indoor Vertical Farming System for Efficient Quality Food Production. Pp. 91-104. Academic Press, San Diego 2016.

Tardieu F., Granier C., Muller B.: Modelling leaf expansion in a fluctuating environment: Are changes in specific leaf area a consequence of changes in expansion rate? - New Phytol. 143: 33-43, 1999.
Wang Q., Zhang Q., Fan D., Lu C.: Photosynthetic light and $\mathrm{CO}_{2}$ utilization and $\mathrm{C}_{4}$ traits of two novel super-rice hybrids. J. Plant Physiol. 163: 529-537, 2006.

Xu W.Z., Deng X.P., Xu B.C.: Effects of water stress and fertilization on leaf gas exchange and photosynthetic light-response curves of Bothriochloa ischaemum L. Photosynthetica 51: 603-612, 2013.

Yan Z., He D., Niu G., Zhai H.: Evaluation of growth and quality of hydroponic lettuce at harvest as affected by the light intensity, photoperiod and light quality at seedling stage. Sci. Hortic.-Amsterdam 248: 138-144, 2019.

Ye Z., Yu Q.: Comparison of new and several classical models of photosynthesis in response to irradiance. - Chin. J. Plant Ecol. 32: 1356-1361, 2008.

Ye Z., Yu Q.: [Comparison of photosynthetic response to intercellular $\mathrm{CO}_{2}$ and air $\mathrm{CO}_{2}$.] - Chin. J. Plant Ecol. 28: 2233-2238, 2009. [In Chinese]

Zhang Q., Zhang T.-J., Chow W.S. et al.: Photosynthetic characteristics and light energy conversions under different light environments in five tree species occupying dominant status at different stages of subtropical forest succession. Funct. Plant Biol. 42: 609, 2015.

Zhang X., He D., Niu G. et al.: Effects of environment lighting on the growth, photosynthesis, and quality of hydroponic lettuce in a plant factory. - Int. J. Agr. Biol. Eng. 11: 33-40, 2018.

(C) The authors. This is an open access article distributed under the terms of the Creative Commons BY-NC-ND Licence. 